\title{
A PROPÓSITO DE "CALIDAD EN LA EDUCACIÓN", REVISTA DEL CONSEJO SUPERIOR DE EDUCACIÓN (CSE)
}

\section{Licenciamiento y acreditación: control y garantía de calidad}

Tal vez sea apropiado observar la importancia que revisten dos procesos independientes pero relacionados con la excelencia y la calidad de la educación superior.

El primero, que la nueva ley define como "licenciamiento", es un control de calidad obligatorio en un sistema que puede recibir nuevos agentes y actores en cualquier momento y que tiene una diversificación tanto horizontal (con actores privados y estatales) como vertical (con distintas opciones institucionales).

Aunque este proceso comporta un grado importante de autoevaluación, las instituciones cumplen más o menos pasivamente las indicaciones del organismo licenciador, el Consejo Superior de Educación, y están sometidas a controles periódicos, visitas de pares y reexaminaciones selectivas. Lo más importante: se trata de un proceso obligatorio, reglado por la Ley Orgánica Constitucional de Enseñanza de 1990, que prescribe plazos y procedimientos no exentos de imprecisiones.

En cambio, el aseguramiento o garantía de calidad es un proceso distinto, en el cual las instituciones ya autónomas, tras un autoexamen evaluativo, señalan y precisan mecanismos para garantizar o asegurar el cumplimiento de metas propias y de estándares generales en forma relativamente voluntaria.

Por una parte, control; por otra, garantía asumida en forma autónoma. 
Se trata, sin embargo, de dos procesos complementarios que deberían afianzar y depurar el sistema de la educación superior chilena, el cual -mirado objetivamente- tiene mucho que mejorar pero también bastante que mostrar de satisfactoria evolución y madura articulación.

En este contexto, por cierto no exclusivo ni excluyente, se busca perfeccionar los mecanismos por los cuales las comunidades universitarias y educativas cumplen sus cometidos y propósitos. Ello conlleva la necesidad de un foro de intercambio de experiencias, ideas y proyectos, y un órgano que permita articular la experiencia y el saber de manera armónica, coherente y productiva.

A esta necesidad responde la revista Calidad en la Educación. Tempranamente en la existencia del CSE sus gestores y administradores sintieron la necesidad de un órgano informativo que articulara una comunidad de práctica bastante indiferenciada y difusa. La revista nació, pues, con la tarea expresa de servir de órgano de comunicación entre distintos partícipes del sistema educativo terciario.

\section{Revistas académicas: de la comunidad de prácticas a la comunidad de conocimiento}

Hacia el año 2001 reconocimos la conveniencia de que la publicación adquiriera un carácter técnico más académico, que consolidara un naciente principio de "scholarship" o intelectualidad en materias que tradicionalmente se dejan libradas a experiencias azarosas de los actores sociales. Cuando efectuamos el cambio, sabíamos que habría un proceso relativamente lento a través del cual metas y audiencias se consolidarían en diálogos con personas e instituciones, en debates, retrocesos y recomienzos, y de esa difusa comunidad de práctica emergería una comunidad de conocimiento cierto, con estándares reconocidos y audiencias conocidas. El proceso ha consistido, pues, en delimitar una comunidad de conocimiento y generar una estructuración disciplinar. 
La historia intelectual indica que el proceso de consolidación disciplinaria siempre ha requerido palabra escrita. Y ésta, en forma de productos primarios, secundarios o terciarios, produce un espacio semántico denso de lectores, con retóricas, cánones y exigencias que configuran procesos sociales y, eventualmente, instituciones aceptadas socialmente.

Así se configura progresivamente un campo disciplinar. Una disciplina es un discurso que crea los objetos de los cuales habla y, al hacerlo, se convierte en parte del paisaje y del tejido social, pues puede enseñarse, otorga dinero, prestigio o poder, y se reconoce como ocupación real sometida a las habituales recompensas de las expertocracias.

La educación terciaria tiene su propia dinámica, sus naturales problemas y diversas soluciones. La universidad, por ejemplo, intenta hacer un universo de partes heterogéneas. Allí conviven personas socializadas en el elitista sistema de la ciencia, individuos que sienten real vocación por enseñar, personas que intentan aplicar determinadas nociones sobre la mejora de la sociedad, economistas que piensan en eficacia y eficiencia, estudiantes que intentan obtener formación y destrezas valoradas por el mercado laboral. Pocas veces se reflexiona sobre la heterogeneidad inherente a la práctica social que conocemos como educación o se examina críticamente el discurso habitual. Ya la Universidad de Berlín de comienzos del siglo XIX abrigaba en su seno esa curiosa tensión entre la erudición, el saber, y la transmisión del conocimiento, el enseñar, pues quienes iban a la universidad deseaban cultivar el saber (lo que a veces llamamos investigar) pero recibían paga por enseñar.

Al destacar una de las tensiones -ingrediente oculto de las dificultades definitorias que hacen difuso y ambiguo el campo- deseo resaltar la importancia de la palabra escrita y, sobre todo, de su preservación bajo la forma de un periódico o una revista. En la perspectiva del tiempo histórico pueden examinarse las tendencias, identificarse los principios, conocer metas y actores. Este proceso 
configura una retórica propia que distingue a los "de dentro" de los "de fuera", permite validar sedicentes experticias, identificar y reconocer quién es quién en un campo de prácticas sociales. La revista se convierte así no sólo en el receptáculo pasivo de ideas más o menos originales. Contribuye activamente a moldear y modular experiencias, teorías, personas. Ese papel es prospectivo, es constructivo, es articulador. Y así quisiera yo justificar la existencia de esta publicación en uno de sus aspectos.

Como en toda configuración disciplinar, puede esperarse que los comienzos mantengan la ambigüedad del magma germinal del cual se recortan las prácticas específicas que luego definirán un campo de estudio y acción. No de otro modo ocurre en el establecimiento de nuevas disciplinas, ciencias, comunidades de expertos: que las nuevas especializaciones se van diferenciando al tenor de intereses de una comunidad que, a través de la palabra, busca legitimación y jerarquización.

\section{Calidad en la educación: una agenda con desafíos}

Esperaría yo que las comunidades de práctica se conviertan en una comunidad de conocimiento, en parte gracias a la revista. Deseo advertir que una comunidad de conocimiento no se caracteriza por las informaciones o datos que intercambia o usa, sino por la arquitectura que da a esas informaciones y datos, por el sentido y orientación que les imprime y por un proceso de extrema importancia: contrastar distintas formas de conocimiento.

Convengamos que hay un conocimiento formal, enseñable y aprendible, por el cual se suele adquirir certificaciones y diplomas reconocidos socialmente. La mayor parte de las profesiones modernas basan su ascendiente social en este tipo de conocimiento.

Existe, además, un conocimiento implícito o tácito que, en general, no tiene el mismo grado de formalización que el anterior, no produce certificaciones con valor social y suele confundirse con 
la vaga noción de "experiencia". Nadie duda que esta vaga noción esconde peligros importantes en actividades que necesariamente requieren confianza pública.

Hay un tercer tipo de conocimiento, que en inglés llamaríamos "embedded". Es el conocimiento incorporado a instituciones, estructuras y prácticas sociales. Por ejemplo, la forma en que una institución universitaria se organiza, los nombres que da a sus dependencias y las metas que construye son el conocimiento "inviscerado", "incorporado" a estructuras sociales y mallas de relaciones.

La diferencia entre esta forma de conocimiento y el anterior consiste en que éste puede ponerse de manifiesto por un observador externo (por ejemplo, un científico social) en tanto el conocimiento tácito puede solamente manifestarse a través de quienes lo han adquirido y usan.

La revista debiera promover los estudios formales y también "descubrir" las prácticas informales, exitosas o fallidas, al tiempo que revela estructuras no evidentes al ojo inexperto.

Debería definirse si será literatura primaria, secundaria, terciaria o cuaternaria la que primordialmente acoja la revista. Considerando que un campo disciplinar las exige todas para ser completo, esta noción integradora debería presidir el diseño futuro. Así, la revista debiera acoger investigaciones originales de corte empírico y datos reproducibles, revisiones de temas substantivos a cargo de especialistas, artículos con carácter de ensayo y reflexión, noticias de publicaciones nacionales y extranjeras y también, idealmente, reacciones de la lectoría frente a los temas tratados. Por ahora, la revista ha tenido un núcleo monográfico en cada edición, acompañada de una sección de estudios, temas misceláneos y noticias de tesis y publicaciones sobre educación superior.

Auguro un papel relevante para esta publicación e invito a quienes pueden ser sus autores y sus lectores a participar de esta 
agenda plena de desafíos en una etapa que inaugura la nueva Comisión Nacional de Acreditación y que se caracterizará por una creciente demanda por informaciones, prácticas y conocimiento.

\section{Bibliografía}

Lolas, F. (1980) Comunication modes in research. In Day, S.B., Lolas, F., Kusinitz, M. (Eds.) Biopsychosocial Health. New York: International Foundation for Biosocial Development, pp. 149-160.

Lolas, F. (1996) Chilean education: an overview (with emphasis on higher education) International Education Forum, 16(2, Fall), pp. 93-97.

Lolas, F. (2004a) La educación superior chilena en tiempos de decisión. Anales del Instituto de Chile, Vol. XXIV (2), pp. 69-81.

Lolas, F. (2004b) Educación superior: valores fundamentales, dilemas permanentes. Anales de la Universidad de Chile, 6a Serie, 16, pp. 33-48.

Lolas, F. (2005) Educación superior y políticas públicas: algunos temas pendientes. Calidad en la Educación, 22, pp. 15-20.

Recibido: 16 marzo de 2007

Aceptado: 30 marzo de 2007 